\title{
A VIOLÊNCIA NO DISTRITO FEDERAL: UM ENSAIO SOBRE A MÍDIA IMPRESSA E A PERSPECTIVA TEÓRICA
}

\author{
Cláudio Ferreira da Silva*
}

\begin{abstract}
Resumo: O artigo A Violência no Distrito Federal: um ensaio sobre a mídia impressa e a perspectiva teórica analisa as características atribuídas pela mídia impressa (Correio Braziliense) à violência. A técnica de pesquisa foi a partir das matérias publicadas neste que é o maior jornal de circulação no Distrito Federal, no caderno "Cidades". O período compreende a segunda quinzena de março, abril, maio e início de junho de 2006. O resultado alcançado revela que a narrativa da violência está vinculada aos conceitos de classe e violência, reiterando a visão de senso comum da existência de uma violência produto da barbárie e pobreza. A perspectiva teórica utilizada destaca a relação entre mídia e realidade, podendo-se afirmar que tal aspecto é também compartilhado pela sociedade local.
\end{abstract}

Palavras-chave: Violência; Distrito Federal; Correio Braziliense;

Abstract The article analyzes the characteristics attributed to violence by the media (Correio Braziliense). The source of research was based on news selected from section "Cities" of the largest newspaper in circulation within the Federal District in the period from March to the beginning of June 2006. Results reveal that the narrative of violence is tied with concepts of social class, reiterating the common sense on the existence of violence as a product of barbarity and poverty. The theoretical perspective highlights the relationship between media and reality, which is also influenced by the local society.

Key-words: Violence. Federal District. Correio Braziliense.

\section{Introdução}

O Correio Braziliense pesquisou o perfil da violência no DF com base em dados de 2005 da Divisão de Estatística e Planejamento Operacional (Depo) da Polícia Civil. A partir de registros fei ${ }^{1}$ tos em todas as delegacias, foi montado o ranking da criminalidade de acordo com a quantidade de casos e moradores. É, evidente, que a pesquisa apresenta problemas de ordem metodológica e analítica simplificada.

O especialista em violência, sociólogo Lúcio de Brito Castelo Branco comenta em artigo publicado no sítio da Universidade de Brasília que o "Raio- $X$ da Criminalidade no DF" destaca a priorização perversa pelas ações criminosas mais rentáveis, o que se evidencia sobretudo no expressivo aumento do roubo a bancos e da prática de seqüestros. Em seguida, chama a atenção o aumento dos estupros (apesar de não haver qualquer especificação ou tipificação desse crime hediondo, porém sempre banalizado em nosso inconsciente coletivo e pela autoridade pública). Há estupros na esfera pública ou privada e o registro dessas ocorrências é sempre inexpressivo diante de sua freqüência real, devido ao constrangimento da vítima. Mas, de qualquer forma, isso indica o crescente desrespeito da integridade da mulher, cada vez mais objetivada em um 
pacote ambulante de pesos e medidas padronizados pela mídia global, e, de forma mais abrangente da pessoa humana em geral, submetida a toda sorte de expropriação.

Os índices relativos a roubos e furtos, apesar de significativos, provavelmente, não expressam a realidade pelo fato de a população viver atemorizada pelas ameaças do banditismo e pela total desproteção da autoridade policial.

No quesito seqüestro relâmpago, o Plano Piloto (com cerca de duzentos mil habitantes) teve 140 ocorrências e ficou em primeiro lugar com sete crimes para cada grupo de 10 mil moradores. As Asas Sul e Norte são de longe os locais onde mais acontecem furtos de veículos. No ano passado, houve 2.511 casos registrados nas duas delegacias do Plano Piloto ( $1^{\mathrm{a}}$ e $2^{\mathrm{a}} \mathrm{DP}$ ), uma média de 125,5 por 10 mil habitantes.

Em números absolutos, a segunda colocada é Taguatinga, com 1.265 ocorrências, que colocam a cidade em terceiro lugar proporcionalmente ao número de moradores. Taguatinga está logo atrás do Plano Piloto também no crime de seqüestro relâmpago.

A cidade ainda é lider absoluta em roubos de veículos. Teve o maior número de registros no ano passado (355), que lhe rendeu uma média de 11,5 ocorrências para cada 10 mil moradores. Nessa modalidade, o Plano Piloto está fora dos cinco primeiros lugares. Antigas invasões têm o maior registro proporcional de dois dos crimes mais violentos. No varjão do Torto, onde moram pouco mais 6 mil pessoas, houve sete assinatos ano passado. Uma média de 14 casos por grupo de 10 mil habitantes. É a região administrativa campeã em homicídios. Em seguida, vem a Estrutural, com um total de 24 casos - 12 para cada 10 mil moradores. O Itapoã, maior favela do DF, ficou quarto lugar, com média de 5,4. A Estrutural lidera em estupros, com média de três ocorrências.

Duas das regiões mais pobres e duas das mais ricas estão entre os cinco lugares do DF com maior quantidade de furtos em residência. Em primeiro e segundo lugares, respectivamente, aparecem Paranoá e Itapoã. Em quarto e quinto, os lagos Sul e Norte. Lá, os moradores têm recorrido à segurança privada para se proteger.

Pelo menos até o fim do ano passado, os moradores do Sudoeste, Octogonal e dos condomínios fechados do Jardim Botânico não tinham preocupação com a violência. As três localidades aparecem nos últimos lugares do ranking dos crimes mais graves contra a vida e o patrimônio registrados 29 regiões administrativas em 2005, segundo os dados da Divisão de Estatística e Planejamento Operacional (Depo) da Polícia Civil. De longe, os dois setores com os apartamentos mais novos e caros do DF tiveram o melhor desempenho das estatísticas. A Região Administrativa Sudoeste/Octogonal não registrou roubo em residência. Nos 12 meses, houve um assassinato. Os dois setores têm quase 50 mil moradores, o mesmo que Brazlândia, com 12 homicídios, e Paranoá, que registrou 30 no mesmo período.

O professor George Felipe Dantas, coordenador do Núcleo de Estudos em Segurança Pública da União Pioneiras de Integração Social (Upis) critica a "concentração de policiamento ostensivo" no Plano Piloto. Para ele, a grande ocorrência de crimes como homicídios e estupros nos locais mais pobres é fruto da ausência do Estado. No caso dos estupros, o professor acredita que os números não correspondem à realidade porque a maioria dos crimes não é registrada. "Os dados 
não representam a criminalidade, que tem uma face oculta. $\mathrm{O}$ estupro mexe com a intimidade social e familiar. Por isso, muitas mulheres não denunciam os criminosos. Elas tem vergonha e medo".

O sociólogo Lúcio de Brito Castelo Branco pontifica que a incidência de seqüestros relâmpagos e furtos de veículos é maior no Plano Piloto por causa da fartura de alvos para os ladrões. "Os dados apontam para uma escolha mais racional do criminoso, pois é justamente nessa área mais sensível que se concentra a riqueza". Ele considera que "os mais ricos vivem também em um sistema prisional, embora confortável e luxuoso".

Nesse período, observou-se uma onda de assaltos em comércios da Asa Norte, a Segurança Pública decidiu voltar com a ronda de duplas de policiais militares nas 68 quadras comerciais do Plano Piloto. Os PM's circulam enquanto as lojas estão abertas. Segundo dados da Segurança Pública, em abril, a criminalidade caiu 10,8\% na Asa Sul e 23,9\% na Asa Norte entre os dias 5 e 17. Para as demais localidades do DF, não foi divulgado dados.

Na área rural do DF a falta de segurança também é fato que merece destaque. A Secretaria de Segurança Pública tem um projeto específico para essa área, elaborado pelo Centro Integrado de Segurança Pública.

\section{Órfãos de Guerra: um retrato dos órfãos da violência no DF}

Em caderno intitulado "Órfãos de Guerra", dia 25 de maio de 2006, o Correio Braziliense listou 731 brasileiros que perderam os pais assassinados no DF em 2005 e a história de 92 deles. Mais de $70 \%$ ainda não haviam completado 21 anos, e 44,1\% tinham menos de 15 anos quando experimentaram a solidão da orfandade. Crescem sem o "colo", sem o "sustento" e sem os "conselhos" paternos ou maternos. A grande maioria vive na periferia. Apenas 10 dos 731 órfãos de homicídios e suicídios ocorridos em 2005 no Distrito Federal moram no Plano Piloto. Muitos são filhos de bandidos e não têm nenhuma culpa disso. Para eles, como para qualquer filho, o pai é um herói e sua ausência, uma tormenta. Vários testemunharam aquilo que nenhuma criança deve ver: a execução de quem mais amavam. É uma visão devastadora que lhes arranca a infância e lhes traumatiza o futuro. São reprovados na escola, sofrem pesadelos, banalizam o crime, prometem vingar o sangue dos antepassados e, alguns, num trágico ciclo, repetem os pais.

O jornal resolveu investigar os sobreviventes, pela completa falta de estatísticas. Durante seis meses percorreram 12 cartórios de registro civil do DF, e examinaram 11.272 certidões de óbitos. Correspondem a todos os falecimentos registrados entre $1^{\circ}$ de janeiro e 31 de dezembro de 2005. Incluem tanto as mortes naturais quanto aquelas provocadas pelas causas externas homicídios, suicídios e acidentes. Ao todo os jornalistas identificaram 1.462 mortes violentas e 2.077 órfãos num único ano. São crianças, adolescentes e adultos que perderam os pais esfaqueados, baleados, espancados, estrangulados, esmagados no trânsito, eletrocutados, queimados, afogados, vítimas de quedas. Causa mortis diferentes com uma triste característica em comum: poderiam ser evitadas. Se nada mudar, daqui a uma década a projeção revela 20 mil herdeiros da barbárie no DF. Números comparáveis com nações em guerra. Só um jeito de parar de produzir meninos sem pais: interromper a guerra urbana. 
Aqui se quebra o tabu de que a violência está presente apenas nas favelas cariocas, nos presídios de segurança não tão máxima de São Paulo e, principalmente, o tabu de que esse fenômeno se encerra na morte, na visão do doutorando em sociologia da UnB, Santiago Falluh Varella.

Para o pesquisador, com as mortes, inicia-se um novo ciclo daqueles que viveram de perto, mas continuaram vivos. Esse ciclo é maior e mais cruel quanto mais jovem se fica órfão. Assim como a intensidade das mortes violentas é maior dentre os mais jovens, na periferia isso se potencializa, já que mais da metade dos órfãos de Planaltina, Recanto das Emas, e Paranoá possuem até 10 anos, enquanto 61\% dos que vivem no Pano Piloto são maiores de 16 anos. Não bastasse a violência em geral atingir principalmente os pais de crianças na primeira infância, $o$ assassinato, sua forma mais cruel, também incide com maior freqüência nesse grupo. Os órfãos do tiro e da faca, mas também da asfixia e do enforcamento, predominam sobre os órfãos do trânsito nos grupos etários mais jovens. Essa tendência se inverte quanto maior a idade das crianças, pois mais tempo se passou, o que aumenta a chance de algo ao acaso, como um acidente de trânsito, ocorrer. Desses assassinatos, 80 \% das crianças órfãs tiveram seu pai ou sua mãe levados pela bala, muito embora a principal ausência deixada pelos tiros é a do pai.

A síntese da crueldade é uma sobreposição de maiorias: a maioria é morta na periferia, a tiros, quase sempre do sexo masculino, pais muito jovens de filhos ainda na primeira infância.

\section{Mídia e violência - discussão teórica}

A discussão teórica tem como referência o artigo "Pedófilo, quem és? A pedofilia na mídia impressa” de Tatiana Savoia Landini para o Caderno Saúde Pública, Rio de Janeiro, 19 (Suplemento 2), páginas 273-282, 2003. A utilização desta parte do artigo justifica-se pela aplicabilidade à proposta de analisar a violência no Distrito Federal a partir do noticiário jornalístico, em especial, o maior jornal de circulação local - Correio Braziliense, entre os meses de março e maio de 2006.

Tanto Zaluar (1999), quanto Michaud (1986), concordam que o termo violência vem do latim violentia, o que, nas palavras de Michaud (1986:4) - as quais estão de acordo com Zaluar significa "violência, caráter violento ou cruel, força. O verbo violare significa tratar com violência, profanar, transgredir. Esses termos devem ser relacionados a vis (...). Mais profundamente, essa palavra vis significa a força em ação, o recurso de um corpo para exercer sua força, e portanto a potência, o valor, a força vital". Segundo a antropóloga brasileira, "essa força torna-se violência quando ultrapassa um limite ou perturba acordos tácitos e regras que ordenam relações, adquirindo carga negativa ou maléfica. É, portanto, a percepção do limite e da perturbação (e do sofrimento que provoca) que vai caracterizar um ato como violento, percepção essa que varia cultural e historicamente" (Zaluar, 1999:28).

Em outras palavras, é possível dizer que existe uma construção histórica e cultural a respeito do que é ou não considerado violência. Interpelar a violência por meio de jornais pode nos levar à compreensão de uma construção social a esse respeito. Colocando de outra forma, buscou-se, com a pesquisa realizada, compreender como a violência é vista e entendida nas matérias do Correio Braziliense, no período pesquisado. 
Com base nessa formulação, a questão seguinte passa a ser: em que medida o jornal pode contribuir para o entendimento da violenta ? Quais suas contribuições? Que tipo de questões têm condições de ser respondidas?

Para Tânia Montoro (1999:106), "todas as formulações já elaboradas a respeito do binômio violência e mídia - quer sejam teóricas, quer de senso comum - são concordantes em que existe uma correlação entre esses dois termos". Uma visão mais tradicional estabelece uma relação de causalidade entre eles, percebendo a violência cotidiana como efeito da mídia - identificando, portanto, uma certa passividade do público receptor. Essa visão mais tradicional seria contestada por estudos mais recentes que demonstram que existe uma interação entre o público e os veículos de comunicação, "o que nos leva a crer que as notícias de violência transmitidas pelos jornais diários, nas telas de TV e nas propagandas radiofônicas, tanto expressam a realidade social como contribuem para (re)criá-la e (re)sedimentá-la em um único movimento" (Montoro, 1999:107).

Ao dizer isso, a autora está partilhando da idéia de que os discursos jornalísticos contêm sentidos que estão previamente na cultura; a notícia é o resultado de um processo de produção no qual há a percepção, a seleção e a transformação de uma matéria-prima em um produto, ou seja, a transformação de um acontecimento em notícia.

É possível, portanto, dizer que, para ela, assim como o acontecimento cria a notícia, a notícia cria o acontecimento. "A notícia seleciona, exclui, acentua diferentes aspectos de um acontecimento, orientando-se por uma narrativa escolhida. É dessa maneira que a notícia constrói a realidade" (Montoro, 1999:120).

Dessa forma, ainda que a autora enfatize a proposição de não passividade do público leitor, não faz menção a qualquer mudança de comportamento desse público em função da mídia. Enfoca apenas a necessidade de que as notícias contenham sentidos culturais, ou seja, que sejam reconhecidos como válidos pelo público leitor.

Uma outra forma de estudo da mídia é a colocada por Adriana Carvalho Lopes (1999). Segundo esta autora, da perspectiva da análise crítica do discurso, "as notícias sobre violência podem ser melhor percebidas como representações da realidade que, construídas como prática regular pelo discurso jornalístico, 'articulam-se com'e 'são modeladas por' o espaço social mais amplo, incluídos o processo histórico e as orientações culturais partilhadas pelos diversos agentes sociais que ordenam a interação oral e escrita" (Lopes, 1999:122).

Para a autora, o discurso jornalístico é regido por contratos institucionais entre o autor e o leitor a tal ponto que o público marcaria, inclusive, a construção de significados, ou seja, os jornalistas criariam o sentido da notícia por meio da incorporação de sentidos do público. Dessa forma, em sua opinião, o jornalismo naturaliza e reproduz comportamentos sociais e relações de desigualdade. Além disso, o jornalista faria sempre uma opção ideológica na medida em que define o que é notícia, como deve ser publicada, com que destaque e favorecimento e o que será excluído e selecionado. Esse processo seria realizado de acordo com diversos critérios, tornando o jornal um veículo de reprodução recortada da realidade. Portanto, como podemos perceber, a visão dessa autora a respeito do binômio mídia e violência não é muito diferente da de Montoro (1999). 
Entretanto, um detalhe é bastante significante: Lopes (1999) enfatiza mais a busca por parte da produção do jornal, dos jornalistas, em capturar os sentidos da violência compartilhados pelo público. Assim, para Lopes, existiria não apenas uma opinião compartilhada pelo público como também o conhecimento dessa opinião por parte do jornal, ou, de forma mais direta, haveria uma homogeneidade do público leitor e um esforço por parte do jornal em tentar capturar essa homogeneidade.

Uma terceira forma de abordar a questão da violência na mídia é a de Adorno (1995). Esse autor, entretanto, introduz uma problemática distinta das anteriores. Seu interesse é discorrer sobre a possibilidade de utilizar a mídia como fonte de informação e pesquisa a respeito da violência e, portanto, em estudar as percepções sociais quanto à criminalidade expressas pela mídia e a correspondência entre essas expressões e dados oficiais "que 'expressariam' a chamada criminalidade real".

Ao realizar essa discussão, Adorno nos coloca que "a construção da criminalidade como um problema social e sociologicamente significativo passa, no nosso entender, pela construção 'marginal' a respeito do crime, do criminoso e da criminalidade e sobretudo pelo conjunto de representações que fazem com que a criminalidade seja hoje um objeto privilegiado de preocupação" (Adorno, 1995:181). A imprensa, em sua opinião, seria um importante veículo de expressão das percepções sociais quanto à criminalidade, ao crime, ao criminoso e ao modo pelo qual a sociedade transforma essa questão num problema de interesse público.

Não podemos exigir, portanto, que o autor realize uma análise a qual não se propôs, e Adorno não tem qualquer pretensão de discorrer sobre o público leitor ou seu comportamento tendo em vista a atuação da mídia. Entretanto, a proposição da mídia como um "importante veículo de expressão das percepções" é de bastante interesse para esta pesquisa, na medida em que introduz um novo elemento: a questão da percepção social da violência.

Elizabeth Rondelli (1998) possui uma quarta visão sobre o binômio violência e mídia. Para ela, os meios de comunicação agem como construtores privilegiados de representações sociais sobre o crime, a violência e aqueles envolvidos em suas práticas e em sua coibição. Nesse sentido, o modo como a mídia fala da violência seria parte da própria realidade da violência, ou seja, de seus atos serão extraídos interpretações e sentidos sociais, os discursos sobre ela passarão a circular no espaço público e a prática social passará a ser informada pelos episódios narrados possuindo, assim, um caráter estruturado e estruturador. "Do real ela nos devolve, sobretudo, imagens ou discursos que informam e conformam este mesmo real. Portanto, compreender a mídia não deixa de ser um modo de estudar a própria violência, pois quando esta se apropria, divulga, espetaculariza, sensacionaliza ou banaliza os atos de violência está atribuindo-lhes um sentido, ao circularem socialmente, induzem práticas referidas à violência" (Rondelli, 1998:149). 
Em suma, Rondelli nos fala sobre a influência das notícias sobre violência no comportamento da população ou, mais especificamente, dos leitores. Tanto Rondelli quanto Adorno estabelecem uma via de mão de dupla entre mídia e comportamento do público, ou seja, a mídia como uma representação socialmente significativa da realidade e o comportamento da população sendo influenciado por essa mesma mídia.

Não é objeto do estudo por mim realizado procurar comprovar a validade dessas teorias, ou seja, estabelecer a relação entre a produção e a recepção da notícia entre a mídia e o público - tal comprovação exigiria uma pesquisa empírica específica. A posição assumida nesta pesquisa é que existe sim uma relação entre o que é noticiado e o que acontece na realidade, relação essa que, entretanto, não significa uma correspondência direta entre os dois fatores, ou seja, a mídia não é um retrato da realidade, mas, ao noticiar certos fatos e colocar ênfase em alguns aspectos em detrimento de outros, a mídia estabelece um recorte significativo não apenas porque contém fragmentos dessa realidade, mas também porque ajuda a criar um sentido, atribuir uma importância aos fatos que estão sendo noticiados.

Dessa forma, ainda que me detenha ao estudo da notícia, é importante apontar tal correspondência para justificar a importância do trabalho realizado e dos resultados obtidos. Em se tratando de violência, o estudo da mídia é ainda mais importante em se considerando o fato de que, sendo um tipo de violência que ocorre na maioria das vezes em ambientes privados, é conhecida pelo público por meio do que dela se fala.

Para Landini (2003) de certa forma, ainda que com outro enfoque, meu objetivo será realizar algo parecido com o que foi feito por Herzlich \& Pierret (1992), ao analisarem, por meio de artigos ou dossiês de jornais franceses coletados entre janeiro de 1982 e julho de 1986, o que chamam de emergência do "fenômeno social da Aids". Para as autoras, "foi a imprensa, que, em sentido estrito, fez existir a Aids para o conjunto da sociedade. Ainda hoje esta afecção só constitui um dado de experiência para um número limitado de indivíduos. Durante muito tempo ela só disse respeito a centenas, depois a alguns milhares, vivendo em lugares afastados uns dos outros: ela se tornou, no entanto, um dos elementos proeminentes de nossa sociedade, conhecida e comentada por todos" (Herzlich \& Pierret, 1992:8).

Landini (2003) destaca que estudar a pedofilia por meio do jornal significa entender os aspectos mais significantes dessa prática. E, nesses aspectos, estão incluídos, dentre outros, a imagem do agressor (quem pratica) e as razões dadas (o porquê). É essa trama de informações que nos mostra o significado do crime para o jornal. O objetivo deste artigo é exatamente estabelecer as principais características atribuídas pela Folha de S. Paulo à pedofilia, procurando mostrar suas peculiaridades em oposição aos outros tipos - estupro, abuso sexual, pornografia e incesto - de violência sexual contra a criança. De forma bastante simplificada, a questão que procurou-se responder com este texto é: para além da definição dicionarizada - amor às crianças ou desejo de práticas sexuais e fantasias sexuais com crianças pré-púberes - e daquela atribuída pela psicologia - uma perversão sexual da ordem da parafilia (C. Abdo, comunicação pessoal) -, como é entendido o termo pedofilia? Ou seja, procurou-se extrair do jornal sua definição "êmica". 
Para Michel Misse, professor do Instituto de Filosofia e Ciências Sociais, a questão da violência não pode ser reduzida aos problemas sociais. Se fosse assim, os mais ricos não cheiravam cocaína e entre os mais pobres não haveria trabalhadores honestos. Destaca que as causas do problema são muitas- passa pelo baixo crescimento econômico e pela concentração de renda. Garante que não existe uma solução final. Exige, porém, que as políticas públicas contra a violência comecem a ser adotadas imediatamente, mesmo que sejam de longo prazo.

O cientista político, Octaciano Nogueira em artigo intitulado "A Lei e a Ordem" diz ser a lei o pressuposto da ordem, e a ordem o sustentáculo da lei. Lei e ordem são instrumentos sobre os quais se assentam a civilização. Lei sem ordem é anarquia e a ordem sem lei é arbítrio. Anarquia e arbitro são sinônimos. Sob o domínio de ambos, frutifica a violência. Todas as formas de violência. A que arma o delinqüente em sua sanha destruidora, e a que instrumentaliza o poder e a autoridade na prática de excessos, desmandos e o emprego imoderado da força.

Com isso, o Brasil está perdendo a capacidade de se indignar tanto com a violência dos criminosos, quanto com a violência das autoridades. Essas que se julgam com o direito de não dar satisfações à sociedade e as que se negam a justificar os seus atos. A impunidade não é regra geral só pela astúcia dos bandidos mas também pela ineficácia das instituições. E o nome disso é anomia.

\section{A segurança pública}

A segurança pública hoje figura entre os quatro principais problemas do País, em companhia da educação, da saúde e do desemprego. Um levantamento feito em abril pelo Instituto Sensus revelou que os eleitores gostariam de ver a segurança pública entre as primeiras preocupações dos governantes, sempre escoltada pelas carências nas áreas de saúde e educação e pela escassez de emprego.

São necessários mais de 100 delegados de polícia no DF para atender o aumento de trabalho nas 44 unidades da Polícia Civil. O quadro é o mesmo de 15 anos atrás, mas número de delegacias e de ocorrências dobrou no período.

Os números da Polícia Civil: 400 delegados trabalham em 44 unidades da Polícia Civil do DF; há 15 anos o quadro permanece inalterado. Nesse período, a criminalidade dobrou no DF; $10 \%$ é a média de vagas no cargo a cada ano, em função de aposentadorias e outros motivos; 109 delegados foram empossados em 2005, para ocupar esse tipo de posto; $\mathrm{R} \$ 8,5$ mil é o piso salarial da categoria; 500 inquéritos por delegado é a média de trabalho, somente na $1^{\text {a Delegacia }}$ de Polícia da Asa Sul; 10 é o número médio de delegados por unidade policial.

A realidade da situação prisional no DF apresenta um excedente de 2.407 detentos acima da capacidade. Segundo a Secretaria de Segurança Pública, a capacidade total das unidades prisionais é de 5.087 detentos, mas atualmente abrigam 7.494, caracterizando um quadro de superlotação. O que leva um contigente de 1.206, de outras áreas, em especial, PM's, bombeiros, e policiais civis à continuarem a trabalhar como agentes penitenciários até a realização de concurso, podendo se estender até fins de 2007. 


\section{Referências Bibliográficas:}

ADORNO, S., 1995. Violência, ficção e realidade. In: Sujeito, O Lado Oculto do Receptor (M. W. Souza, org.), pp. 181-188, São Paulo: Brasiliense.

CORREIO BRAZILIENSE, 2006. Órfãos de Guerra. Correio Braziliense, Brasília, 25 de maio, Caderno Especial.

CORREIO BRAZILIENSE, 2006. Uns na guerra outros na paz. Correio Braziliense, Brasília, 28 de maio, Caderno Cidades.

CORREIO BRAZILIENSE, 2006. Artigo: A lei e a Ordem, Octaciano Nogueira. Correio Braziliense, Brasília, 31 de maio, Opinião.

CORREIO BRAZILIENSE, 2006.Delegados em falta. Correio Braziliense, Brasília, 31 de maio, Caderno Cidades.

CORREIO BRAZILIENSE, 2006.Fora da função por mais um ano. Correio Braziliense, Brasília, 06 de junho, Caderno Cidades.

HEILBORN, M. L. \& BRANDÃO, E., 1999. Introdução: Ciências sociais e sexualidade. In: Sexualidade - O Olhar das Ciências Sociais (M. L. Heilborn, org.), pp. 7-17, Rio de Janeiro: Jorge Zahar.

HERZLICH, C. \& PIERRET, J., 1992. Uma doença no espaço público: A AIDS em seis jornais franceses. Physis, 2:7-35.

JORNAL DO BRASIL, 2006. Entrevista Michel Misse. "Estamos matando demais". Jornal do Brasil, 04 de junho, Caderno Segurança Pública.

JORNAL DO BRASIL, 2006.Combate à violência é missão nacional. Jornal do Brasil, 04 de junho, Caderno Segurança Pública.

LANDINI, T. Savoia, 2003. Pedófilo, quem és? A pedofilia na mídia impressa. In: Caderno Saúde Pública, 19, Suplemento 2, pp. 273-282, Rio de Janeiro.

LOPES, A. C., 1999. Violência contra mulheres na mídia impressa. In: Violência, Gênero e Crime no Distrito Federal (M. Suárez \& L. Bandeira, org.), pp. 121-143, Brasília: Paralelo 15/Editora Universidade de Brasília.

MICHAUD, Y., 1986. La Violence. Paris: Presses Universitaires de France.

MONTORO, T., 1999. Notícias de violência: Uma leitura. In: Violência, Gênero e Crime no Distrito Federal (M. Suárez \& L. Bandeira, org.), pp. 105-120, Brasília: Paralelo 15/Editora Universidade de Brasília.

PARKER, R., 1999. Cultura, economia, política e construção social da sexualidade. In: $O$ Corpo Educado: Pedagogias da Sexualidade (G. L. Louro, org.), pp. 125-150, Belo Horizonte: Autêntica.

RONDELLI, E., 1998. Imagens da violência: Práticas discursivas. Tempo Social: Revista de Sociologia da USP, 10:145-157.

ZALUAR, A., 1999. Violência e crime. In: O Que Ler na Ciência Social Brasileira, v.1 Antropologia. São Paulo: Editora Sumaré/Associação Brasileira de Pós-Graduação em Ciências Sociais. 